The Psychological Record, 2010, 60, 489-504

\title{
ESTABLISHING COMPLEX DERIVED MANDING WITH CHILDREN WITH AND WITHOUT A DIAGNOSIS OF AUTISM
}

\author{
Carol Murphy and Dermot Barnes-Holmes \\ National University of Ireland, Maynooth, Ireland
}

\begin{abstract}
Participants were four 14-year-old adolescent boys with diagnosed autism spectrum disorder and 3 children without diagnosed learning disorders aged 5 to 11. Training trials to establish more/less relational functions for 2 stimuli ( $X$ and $Y$, respectively) were interspersed with training trials to establish comparative relations among 5 other arbitrary stimuli (i.e., $A$ is more than $B, B$ is more than $C, C$ is more than $D$, and $D$ is more than E). Subsequent tests showed a derived transformation of functions for 7 participants (i.e., derived more/less mands). Exemplar training was required with 2 children. An ABA design with 3 participants showed manding was controlled by trained relations.
\end{abstract}

Key words: autism, children, derived mands, language, more/less relations

Recent behavioral research has sought to develop procedures for establishing "generative" manding with children with autism and with adults with learning impairment (Murphy \& Barnes-Holmes, 2009a; Murphy, BarnesHolmes, \& Barnes-Holmes, 2005; Rehfeldt \& Root, 2005; Rosales \& Rehfeldt, 2007). The term generative in this context refers to responding that is emitted in the absence of a direct history of reinforcement, and a mand is commonly known as a request. The mand is one of several verbal operants (e.g., mands, tacts, autoclitics, intraverbals, textual responding) identified by Skinner (1957) in a behavioral account of human language. According to Skinner's definition, a mand response specifies its own reinforcer-for example, "May I have water?" Manding thus affords a child control of his or her environment via the social mediation of a "listener."

Because of its importance in affording indirect environmental control, the mand is usually the first response targeted when researchers are training language in applied settings with children with autism (Sundberg \& Michael, 2001). In addition to a directly trained mand repertoire, however, the emergence of novel manding through the establishment of a derived mand repertoire could be very beneficial to language training in an applied

The current study was partially funded by the Research and Graduate Studies Department at NUI Maynooth. Partial funding was also provided by the Irish Council for Research in the Humanities and Social Sciences.

We express our appreciation to the following people for their cooperation and assistance throughout the current research: Mark Ryan, Niamh Lane Kelly, and teachers who functioned as second investigators at a remedial unit that facilitated the current research.

Correspondence should be addressed to Carol Murphy at the Department of Psychology, National University of Ireland Maynooth, Co. Kildare, Ireland. E-mail: Carol.A.Murphy@nuim.ie 
setting. Teaching an individual to emit appropriate mand responses frequently involves motivating operations (MOs; Laraway, Snycerski, Michael, \& Poling, 2003; Michael, 1993) to temporarily alter the reinforcing effects of stimuli. For example, arranging mild water deprivation may enhance motivation when teaching a child to mand for water. The current program of research on derived mands used a board-game format, and absent or surplus tokens on the board were used to evoke derived manding for more or fewer tokens.

Previous studies that have sought to establish derived manding have used the concept known as the derived transfer of functions (Murphy \& Barnes-Holmes, 2009a; Murphy \& Barnes-Holmes, 2009b; Murphy et al., 2005; Rehfeldt \& Root, 2005; Rosales \& Rehfeldt, 2007), a behavioral process that is thought to be pervasive throughout natural human language (Hayes, BarnesHolmes, \& Roche, 2001). Derived transfer effects are related to the phenomenon known as stimulus equivalence, in which directly acquired relations between a number of stimuli result in the untrained emergence of additional relations, such that each stimulus becomes functionally equivalent to the other (Sidman, 1971). Consider, for example, a child who is taught that milk is the same as bainne (Irish), and who later learns that bainne is the same as lait (French). The three stimuli may then come to participate in an equivalence relation, in that the child may subsequently derive that lait is equivalent to milk even though this relation has not been explicitly reinforced. A derived transfer of mand functions could then occur if the child, having learned to mand for milk, spontaneously manded for lait. In effect, the mand function that was directly trained for milk transfers via an equivalence relation from milk to lait via the mediating bainne stimulus. The derived transfer of functions via equivalence relations has been well documented in the experimental literature (e.g., Barnes, Browne, Smeets, \& Roche, 1995; Dougher, Auguston, Markham, Greenway, \& Wulfert, 1994; Dymond \& Barnes, 1994).

The studies on derived manding referred to previously attempted to combine the concept of derived transfer with Skinner's concept of the mand as a means of establishing novel manding. We have argued that establishing derived responding in addition to directly reinforced responding may be important in terms of promoting generative and flexible verbal behavior in children with autism, because this population frequently demonstrates excessive behavioral and verbal rigidity (Murphy \& Barnes-Holmes, 2009b; Murphy et al., 2005).

In the first study of the current series (Murphy et al., 2005), a board game required that children mand with one of two nonsense syllables for one of two specific tokens (e.g., blue or yellow). Results showed that all seven children with diagnoses of autism successfully demonstrated what was termed a derived transfer of mand functions (untrained, or "derived," mands). In short, this study was the first clear demonstration of a derived or generative form of one of Skinner's (1957) verbal operants with children with autism.

Murphy and Barnes-Holmes (2009b) sought to extend the work of Murphy et al. (2005) with four children (aged 7-11) diagnosed with autism, and this second study demonstrated two different classes of derived mand, one functioning as a request for "more" and the other as a request for "less." All four participants successfully demonstrated derived more/less manding, and two children showed this derived transfer performance in the absence 
of any programmed differential consequences. This demonstrated the robustness or reliability of the derived transfer effect in the current context. To further develop complexity in derived manding with individuals with autism, a third study conducted by Murphy and Barnes-Holmes (2009a) sought to establish five specific derived relational mands in the absence of programmed differential consequences. Participants in this study demonstrated derived manding for $-2,-1,0,+1$, and +2 tokens.

The derived mand studies described thus far involved a derived transfer of functions in accordance with equivalence-type relations. That is, the specific mand functions were originally trained with the A stimuli before subsequently emerging for the $C$ stimuli via A-B-C equivalence relations (Murphy \& Barnes-Holmes, 2009a, 2009b; Murphy et al., 2005). In terms of developing flexible verbal repertoires and building up complexity in derived manding, however, it may also be advantageous to establish emergent manding based on a derived transformation of functions.

Derived transformation of functions is a term used when stimulus changes occur as a function of derived relations that are nonequivalent (Hayes et al., 2001). For example, researchers have demonstrated derived relations such as more than/less than, same/different, and before/after (Dymond \& Barnes, 1995; Green, Stromer, \& MacKay, 1993; Roche \& Barnes, 1996; Roche \& Barnes, 1995; Steele \& Hayes, 1991; Whelan, Barnes-Holmes \& Dymond 2006). When the functions of stimuli are altered based on derived relations that are nonequivalent, it seems inappropriate to apply the term transfer. Imagine, for example, that a child is taught that 5 is more than 2, and the child subsequently derives that 2 is less than 5 . In this case, the "less than" function derived for " 2 " cannot accurately be said to "transfer"; rather, the function might be said to "transform" based on the trained relation (see Hayes et al., 2001, for a full account). The current study sought to establish derived manding based on a transformation of functions in participants with and without autism. If successful, this would be the first published study to demonstrate a derived transformation with children, and would serve to extend our earlier work on derived transfer of mand functions.

Participants were first exposed to match-to-sample (MTS) training to establish more and less functions for two arbitrary stimuli (X and Y, respectively; see also Murphy \& Barnes-Holmes, 2009b). Specifically, in the presence of Sample X, selecting a long line of tokens was reinforced, and in the presence of Sample Y, selecting a short line of tokens was reinforced. Participants were also exposed to conditional discrimination training that used the $\mathrm{X}$ and $\mathrm{Y}$ stimuli to establish comparative relations among a range of other arbitrary stimuli as follows: $\mathrm{A}$ is more than $\mathrm{B}, \mathrm{B}$ is more than C, C is more than D, and D is more than E. That is, during conditional discrimination training, either X ["more"] or Y ["less"] was presented above two comparisons ( $\mathrm{A}$ and $\mathrm{B}$, or $\mathrm{B}$ and $\mathrm{C}$, or $\mathrm{C}$ and $\mathrm{D}$, or $\mathrm{D}$ and $\mathrm{E}$ ), and reinforcement was delivered for choosing $\mathrm{A}$ not $\mathrm{B}$ given $\mathrm{X}$, and $\mathrm{B}$ not $\mathrm{A}$ given Y; the same contingencies were applied to the B-C, C-D, and D-E pairs. A subsequent test procedure sought to determine whether derived manding would emerge in accordance with the trained relations (i.e., would participants mand for +2 tokens with stimulus $A$, for +1 token with $B$, for -1 token with $\mathrm{D}$, and for -2 tokens with $\mathrm{E}$ ? A verbal instruction prompted participants to mand for 0 tokens with $\mathrm{C}$, but prompts were not delivered for the other mands). Finally, an ABA reversal design was conducted with four 
participants to demonstrate that the derived manding was under the control of the trained conditional discriminations.

\section{General Method}

\section{Participants}

Four participants (Colm, Steven, Paul, and John) were 14-year-old boys with diagnosed autism spectrum disorder. Each individual diagnosis had been provided by an independent clinical psychologist, with no involvement in the current or related research, in accordance with DSM IV criteria (American Psychiatric Association, 2000). Colm, Steven, and Paul attended a remedial educational unit on a full-time basis for learning difficulties related to their diagnosed autism. John spent a number of school hours per week at the same unit because of learning problems related mostly to social behaviors, but otherwise he attended a school for typically developing boys that the unit was attached to (located in Co. Kildare, Ireland). These four participants all had verbal repertoires that included several hundred mands, tacts, and intraverbals that they could apply in a range of situations. Colm, however, was described by a speech and language therapist as having a deficient vocabulary. Steven's speech tended to perseverate on topics of particular interest to himself; in addition, he frequently applied inappropriate verb tense during speech episodes. Paul's speech was somewhat slurred. None of these three boys was described as high-functioning, and none had acquired fluency in basic reader/writer skills or basic mathematics (i.e., the boys could not fluently add or subtract more than single digits). John's speech was, in general, similar to that of his typically developing peers, as was his academic performance in addition and subtraction.

Three other participants (Neil, Mary, and Gareth) were children aged 5 to 11 who had no diagnosed learning disorders and attended a school for normally developing children. Although Gareth had recently begun attending a mainstream school, as a preschooler he had been provided with ABA home tuition because of a severe speech delay reported by his parents. At the time of the current research, Gareth was doing well academically at school and was ahead of his peers at reading and math. Nevertheless Gareth's teachers reported problems related to social skills and listening in class, and thus Gareth continued to have ABA home tuition to develop his listening skills. All except one participant (John) had been involved in a previous study on derived manding that was based on equivalence relations (Murphy \& BarnesHolmes, 2009a).

\section{Experimental Setting}

The experimental procedures for the boys with autism were conducted in the children's general education classroom. The three other children completed the experimental procedures in their private homes. A desk and two chairs were used in all experimental phases, with participants seated on one side, facing the investigator, who was seated on the opposite side. For all test phases, a third chair was placed to one side of the desk (out of direct eye contact with the child), and the investigator moved to this chair while a second investigator sat in the first investigator's chair. The second investigator 
conducted all tests and recorded data independently but remained unaware of or "blind" to experimental objectives. The first investigator simply functioned to record data separately for the purposes of interobserver agreement. Procedures were thus designed to prevent the possibility of subtle cueing.

The seven participants performed all training and test trials individually, and sessions were usually conducted three or four times a week with each child. Sessions were always interspersed with frequent 2- to 5-min breaks, during which participants could engage in a different activity of their choice. The number of sessions required to complete the experiments ranged from 12 to 20 across participants. The duration of sessions was never more than $1 \mathrm{hr}$, and if a child showed any sign of distress or boredom, sessions were terminated and resumed at a later date.

\section{Materials}

All materials were prepared using colored laminated cards. The stimuli used for establishing more/less relations, conditional discriminations, and tests for derived mands consisted of seven nonsense syllables printed on the laminated cards $(10$ by $6 \mathrm{~cm})$. In the current report the syllables are referred to as $X, Y, A, B, C, D$, and $E$; participants were never exposed to these labels. Three different sets of A, B, C, D, and E stimuli were employed. The first set was used for the board game practice trials (see below, Table 1); Set 2 was used for the experiment proper, and Set 3 was employed following exemplar training with Set 2. Tests for derived mands also involved a rectangular board $(30 \mathrm{~cm}$ by $20 \mathrm{~cm}$ ) that had a center panel outlined in black containing six circles, each of which was also outlined in black, upon which tokens were placed during test procedures. Tokens used throughout the experiment were 8 -cm disks with printed smiley faces. Finally, after exemplar training with one participant, five additional nonsense syllables were used in a novel procedure. These novel stimuli are also labelled A-E for ease of reading, but it is important to note that they were not seen before by the participant.

Table 1.

Arbitrary Stimuli Used in Training and Test Procedures

\begin{tabular}{cccccccc}
\hline & A & B & C & D & E & X & Y \\
\hline Set 1 & PID & TUR & ZOC & FIL & JAS & O & O \\
Set 2 & DAX & CUL & RIW & SUS & EEB & & \\
Set 3 & TEM & LII & YEX & ALC & PEM & & \\
\hline
\end{tabular}

\section{Interobserver Agreement}

Interobserver agreement was obtained by having two investigators record data independently across all test procedures for each participant. This involved writing the nonsense syllable presented as a mand by participants on a prepared sheet. Interobserver agreement was calculated by dividing the total agreements by the number of agreements plus disagreements and multiplying by $100 \%$. Agreement was calculated for all tests and was $95 \%$ across participants. 


\section{Procedure}

Board game practice trials. A board game procedure was used to evoke manding for specific amounts of tokens, similar to a transitive conditioned motivating operation (CMO-T; see Laraway et al., 2003; Michael, 1993). A motivating operation refers to the manipulation of setting events (e.g., deprivation to increase the effectiveness of a mand consequence) and is a procedure used frequently in mand training. A CMO-T involves procedures that manipulate indirectly acquired or conditioned reinforcers, such as the tokens employed in the current study. All participants were exposed to a board game practice procedure.

A board containing six circles had to be filled with six tokens. Participants were required to mand with particular stimulus cards for the addition or removal of amounts (more/less) of tokens to retain a set of six in the center panel. Board game practice trials established "winning a game" as a conditioned reinforcer for participants using verbal praise (e.g., "That's great, you're winning"). Each mand stimulus card had a different printed nonsense syllable, designated in the current report with alphabetic letters. Such stimuli are often employed in derived transfer studies to prevent confounding influences due either to physical similarities between stimuli or to participants' learning histories outside the experimental context. During board game practice trials the mands were reinforced, but during tests for derived manding there were no programmed differential consequences.

Board game practice trials involved placing the token board on the desk in front of participants with an array of mand stimulus cards (Set 1: A, B, $\mathrm{C}, \mathrm{D}$, and E) placed in random order approximately $12 \mathrm{~cm}$ below. The investigator told participants that the center panel of the board should be filled with no more and no less than six tokens. On a trial in which the child was required to mand for additional tokens, the investigator placed less than six tokens on the circles in the center panel. On a trial in which the child was required to mand for the removal of tokens, the investigator covered each of the six circles with a token and placed additional tokens in the space outside the panel. Finally, on a trial in which the child was required to mand for neither the addition nor the removal of tokens, the six circles were each covered by a token, and no additional tokens were placed outside the panel. Thus, empty circles in the center panel served as visual prompts for absent tokens, and the outline of the panel served to emphasize that tokens present outside the line were surplus (i.e., more than were needed).

Participants were instructed to mand to gain or lose specific amounts of tokens by presenting one of the five mand stimuli (A, B, C, D, and E) to the investigator. The amount of tokens required might be $+2,+1,0,-1$, or -2 , and the participant had to mand for these specific amounts with A, B, C, D, or E, respectively. Thus, for each trial, the investigator placed amounts of 4 , $5,6,7$, or 8 tokens on the board, and participants had to mand for correct amounts to make six tokens. Initially, mand training trials presented participants with the mands D and E only; thus, the investigator placed either seven or eight tokens on the board, saying, "Let's play a game. Look at the board and count the tokens. You must have 6 tokens here (pointing to the center). If there are 8 tokens, like now, give me this card (E) to lose 2 tokens. If there are 7 tokens, give me this card (D) to lose 1 token." 
The investigator delivered positive reinforcement for correct manding (i.e., manding with $\mathrm{E}$ when presented with eight tokens on the board, or manding with $\mathrm{D}$ when there were seven tokens on the board). Positive reinforcement involved delivery of 1 "point" (points system) paired with verbal praise (e.g., "That's right" or "Well done"). Points were later used to access backup reinforcers, such as toys/games/activities/edibles, and participants were allowed to have a 2- to 5-min break when availing themselves of backup reinforcers.

If a participant manded incorrectly, the investigator delivered no positive reinforcement, presented or removed the (incorrect) number of tokens manded, delivered a correction, cleared the board, and began the next trial. For example, if a participant manded with D (the mand for -1 token) when presented with eight tokens on the board, the investigator removed one token, saying, "You should have given me this card [pointing to E] because you needed to lose two tokens," and then moved onto the next trial. As participants became proficient at manding with $\mathrm{D}$ or $\mathrm{E}$, the investigator gradually introduced manding with $\mathrm{A}, \mathrm{B}$, and $\mathrm{C}$ across subsequent trials. Participants were thus taught to mand consistently for specific amounts of tokens by presenting the correct card to the investigator.

Training $\mathrm{X} / \mathrm{Y}$ more/less relational functions. A match-to-sample procedure was used with two arbitrary stimuli, $X$ and $Y$; the $X$ stimulus was established as functionally equivalent to more, and $\mathrm{Y}$ as functionally equivalent to less. The investigator placed one sample stimulus, either X or Y, approximately $12 \mathrm{~cm}$ above two comparison stimuli on a desk in front of the participant (see Figure 1 for a visual representation). The comparison stimuli were two separate horizontal rows of tokens, with one row containing more tokens than the other (e.g., five versus four; the comparison stimuli always contained between one and five tokens). Participants learned to select the row with more tokens in the presence of sample $X$, and to select the row with less tokens given the sample $\mathrm{Y}$.

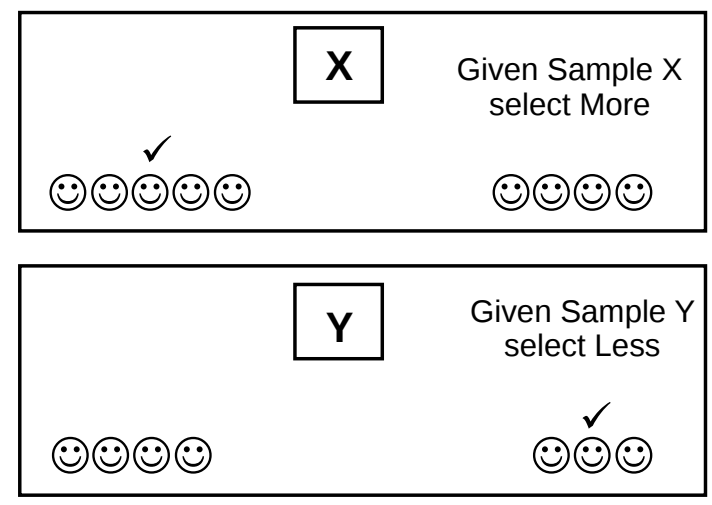

Figure 1. Training "more" and "less" functions with $\mathrm{X}$ and $\mathrm{Y}$ stimuli.

During the first two trials, the investigator instructed participants to "Point here" (indicating the row with five tokens if the sample was X, or to the row with four tokens if the sample was Y). On trials thereafter, the investigator simply waited for the participant to point, or, if necessary, prompted by saying, "Point, please." If the participant selected the row of five tokens 
in the presence of sample $X$, the response was reinforced with immediate verbal praise (e.g., "Good, that's right”) paired with 1 point. If the participant selected the row with four tokens in the presence of sample $X$, the investigator delivered a correction by gently guiding the child's hand to the longer row, saying "Point here," and no positive reinforcement was delivered. If the sample was Y, selecting the row with four tokens was reinforced, and selecting the row with five tokens resulted in delivery of corrective feedback and no positive reinforcement.

Presentation of the sample stimuli X/Y was quasirandom and counterbalanced such that each stimulus appeared an equal number of times within each block of trials (see below). The left/right position of the two rows of tokens (short and long) was also quasirandom and counterbalanced across trials.

Training baseline A-E relations. Following the first four X/Y more/ less relational function trials, training was introduced to establish comparative relations among a range of arbitrary stimuli (Set 2: $A>B, B>C, C>D$, $\mathrm{D}>\mathrm{E}$ ). These $\mathrm{A}-\mathrm{E}$ relational training trials were interspersed among the $\mathrm{X} / \mathrm{Y}$ more/less trials. Initially, the four $\mathrm{X} / \mathrm{Y}$ trials were followed by five A-E trials; thereafter, only two $\mathrm{X} / \mathrm{Y}$ trials were presented between each block of five A-E trials.

For each A-E trial, the investigator positioned one of the sample stimuli $\mathrm{X}$ or $\mathrm{Y}$ on the desk in front of the participant, approximately $14 \mathrm{~cm}$ above two comparison stimuli (e.g., A and B). For the first two trials, the investigator gave a simple instruction to participants (e.g., when the sample was $X$, "Point here [A]," and when the sample was Y, "Point here [B]"). As trials continued, the investigator simply placed the sample and waited for participants to point. If a participant made a correct selection, the investigator delivered positive reinforcement (as described previously). If a participant made an incorrect selection, the investigator gave corrective feedback indicating the stimulus to be selected, and delivered no positive reinforcement. Presentation of samples was quasirandom and counterbalanced across trials, as was the left/right position of comparison stimuli. The same general procedure was used to train the $\mathrm{B}>\mathrm{C}, \mathrm{C}>\mathrm{D}$, and $\mathrm{D}>\mathrm{E}$ relations. That is, when $\mathrm{X}$ was presented as a sample, choosing B over C, C over D, and D over E was reinforced; when $Y$ was presented as a sample, choosing $C$ over $B, D$ over $C$, and $\mathrm{E}$ over $\mathrm{D}$ was reinforced. The $\mathrm{A}-\mathrm{E}$ relations were trained in successive pairs (i.e., $A>B, B>C, C>D$, and $D>E$ ), with each pair being trained in blocks of 30 trials, including the interspersed pairs of $\mathrm{X} / \mathrm{Y}$ more/less relational function trials (20 A-E and $10 \mathrm{X} / \mathrm{Y}$ trials per block). The criterion for successful completion for each set of relations was a minimum of 26/30 trials for two successive blocks with no errors across the final 15 trials.

Test I: Derived transformation of relational mand functions. When participants had successfully completed training for the X/Y more/less relational functions and the AE comparative relations, they were exposed to a test for derived transformation of relational mand functions. To evoke derived manding, the test used a board game format similar to that employed for the practice trials that differed in the following details. The investigator took a seat to one side of the desk, and a second investigator replaced the first, sitting opposite the participant. The investigator placed six tokens on the six circles on the board and delivered the following instructions (no subsequent verbal interaction took place between the investigator and participant throughout each test): 
You must give Niamh [or other second investigator] the right card to gain or lose tokens so that you keep 6 tokens here [pointing to the panel with 6 tokens]. If the board has 6 tokens, like now, you don't need to gain or lose tokens, and so you would give Niamh this card [indicating "C"] for zero tokens. If the board has 5 tokens [removing one token], you must look at all the cards below and see which one you would give Niamh to gain one token. If there are 7 tokens, look and see which card you would give Niamh to lose one token. We're not going to tell you if you're right until the end, and we won't give or take away tokens.

The foregoing instructions thus established that the $\mathrm{C}$ stimulus would function as a mand for obtaining zero tokens, and that no immediate differential feedback would be provided for manding with the remaining four stimuli (A, B, D, and E). Neither investigator delivered programmed differential consequences for correct or incorrect mands during test trials. Instead, each time a participant manded, the investigator simply cleared the board and moved on to the next trial. During Test 1, participants were required to mand for $+2,+1,0,-1$, and -2 tokens, with A, B, C, D, and E, respectively (see Figure 2). Across the three initial test trials, participants were presented with B, C, and D only, and endpoints in the series, A and E, were not included. For all remaining trials, the investigator presented all five A-E stimuli in random order. This pattern of manding was defined as a derived transformation of relational mand functions. The order of trial presentations was quasirandom, ensuring that participants had to mand at least five times with each of the four stimuli (A, B, D, and E). Test trials were counted in blocks of 20, not including the initial three trials. The criterion for successful completion of Test I was a block of 20/20 correct derived mands or at least 18/20 for two successive blocks. Investigators recorded each mand presented by participants by writing the nonsense syllable on a prepared score sheet. The second investigator remained unaware as to whether the mand response was correct or incorrect.



Figure 2. Test I: Probe for baseline derived relational mands

Training reorganized A-E relations. This manipulation of trained A-E comparative relations was designed to function in a manner similar to a return to baseline in a withdrawal-design experiment. Thus, training to 
reorganize A-E relations was followed by a test to determine whether the derived mands changed accordingly. Subsequently, the baseline A-E relations were retrained and a test probed for a return to the original derived mands. These procedures were conducted with four of the participants, one of whom had a diagnosis of autism (time constraints prohibited extending reversal treatments to all participants). The training procedure for reorganizing A-E relations was similar to the original training except that in the presence of Sample X, differential reinforcement was provided for choosing the comparison C over A, A over D, D over E, and E over B, and in the presence of Sample $\mathrm{Y}$, reinforcement was delivered for choosing A over C, D over A, E over D, and B over E.

Test II: Five reorganized derived relational mands. The procedure was similar to that for Test I, except that participants were required to mand for, $+2,+1,0,-1$, and -2 tokens, with $\mathrm{C}, \mathrm{A}, \mathrm{D}, \mathrm{E}$, and $\mathrm{B}$, respectively. In addition, on this occasion the investigator delivered instructions to participants prior to testing that they should mand for zero tokens with the D stimulus (rather than the $\mathrm{C}$ stimulus, as before).

Retraining original A-E relations. If participants demonstrated derived relational manding based on the newly trained A-E relations, they were exposed to training to reestablish the original A-E relations. These relations were trained exactly as before.

Test III: Return to original derived relational manding. Test III was conducted exactly as Test I.

Exemplar training. If a participant failed to demonstrate derived relational manding during the first test procedure (Test I), he or she was subsequently exposed to explicit training for the desired transformation of relational mand functions. Specifically, the participant was trained to mand with $\mathrm{A}, \mathrm{B}, \mathrm{C}, \mathrm{D}$, and $\mathrm{E}$, for $+2,+1,0,-1$, and -2 tokens, respectively. In effect, the exemplar training trials were similar to trials described under "Board game practice trials," but the A-E stimuli were those used during the experimental procedure. When the exemplar training was completed, the participant was exposed to a similar second experimental procedure but with novel A-E stimuli (Set 3).

\section{Results}

The data for training and testing for the derived transformation of relational mand functions are presented in Table 2. For ease of reading, the term will be shortened to derived manding throughout the rest of the current section. During training to establish X/Y relational functions and baseline A-E relations, Neil (typically developing) required no more than two 30-trial blocks for each pair of relations $(A>B, B>C, C>D$, and $D>E)$. The data for Neil for Test 1 showed derived manding (100\% correct; manding for $+2,+1,0,-1$, and -2 , with A, B, C, D, and E). During training to reorganize the A-E relations Neil again required no more than two 30-trial blocks for each novel set of relations $(C>A, A>D, D>E, E>B)$. When subsequently exposed to Test II, he demonstrated reorganized derived manding in accordance with the novel relations (90\% correct; manding for $+2,+1,0,-1$, and -2 , with $\mathrm{C}, \mathrm{A}, \mathrm{D}, \mathrm{E}$, and B). Neil completed training to reestablish the baseline A-E relations, and then demonstrated original derived manding (90\% correct). 
Table 2.

Participant Data for Training and Test Trials

\begin{tabular}{|c|c|c|c|c|c|c|}
\hline \multirow[t]{2}{*}{ Participants } & \multirow[t]{2}{*}{$\begin{array}{c}\text { Exemplar } \\
\text { training }\end{array}$} & \multicolumn{5}{|c|}{$\begin{array}{l}\text { Training and testing for derived transformation } \\
\text { of more/less mand functions }\end{array}$} \\
\hline & & $A>B$ & $B>C$ & $C>D$ & $\mathrm{D}>\mathrm{E}$ & Test I \\
\hline Neil & & 30 & 26,29 & 30 & 28,29 & $20(100 \%)$ \\
\hline Mary & & 27,28 & 27,29 & 30 & 30 & $20(100 \%)$ \\
\hline John & & 30 & 27,30 & 30 & 29,29 & $20(100 \%)$ \\
\hline Steven & & $25,28,29$ & 28,30 & $25,28,30$ & 28,27 & $20(100 \%)$ \\
\hline Colm & & 27,27 & 28,27 & 28,28 & 28,28 & 20 (100\%) \\
\hline Paul & & 28,30 & 30 & 30 & 27,29 & $12(60 \%)$ \\
\hline Paul & 30,30 & 30 & 30 & 30 & 30 & $20(100 \%)$ \\
\hline Gareth & & 30 & 30 & 30 & 30 & $6(30 \%)$ \\
\hline \multirow[t]{3}{*}{ Gareth } & 30,29 & 30 & 30 & 30 & 30 & 20 (100\%) \\
\hline & & \multicolumn{5}{|c|}{$\begin{array}{l}\text { Training and testing for reorganized derived transformation } \\
\text { of more/less mand functions }\end{array}$} \\
\hline & & $C>A$ & $A>D$ & $D>E$ & $E>B$ & Test II \\
\hline Neil & & 30 & 27,28 & 30 & 30 & $18,18(90 \%)$ \\
\hline Mary & & 28,28 & 27,28 & 30 & 30 & $8(40 \%)$ \\
\hline Mary & & 30 & 28,27 & 30 & 27,30 & 18,19 (92\%) \\
\hline \multirow[t]{3}{*}{ John } & & 30 & 28,28 & 30 & 30 & $18,18(90 \%)$ \\
\hline & & \multicolumn{5}{|c|}{$\begin{array}{l}\text { Training and testing for return to baseline derived transformation } \\
\text { of more/less mand functions }\end{array}$} \\
\hline & & $A>B$ & $B>C$ & $C>D$ & $\mathrm{D}>\mathrm{E}$ & Test III \\
\hline Neil & & 30 & 29,28 & 28,29 & 30 & $18,18(90 \%)$ \\
\hline Mary & & 30 & 29,29 & 28,30 & 30 & $20(100 \%)$ \\
\hline John & & 30 & 28,30 & 29,30 & 30 & $18,18(90 \%)$ \\
\hline
\end{tabular}

Mary (typically developing) completed training procedures with no difficulties and subsequently showed derived manding (Test I: 100\% correct). After training to reorganize the A-E relations, however, Mary failed Test II ( $40 \%$ correct). She was exposed to additional training in the novel relations (two 30-trial blocks of training trials for each set of relations) and went on to show reorganized derived manding (92\% correct). Mary then underwent retraining in the baseline A-E relations, and when subsequently exposed to Test III, she demonstrated a return to the original derived relational mands (100\% correct).

Subsequent to experimental training procedures, John (diagnosed with autism) showed derived manding (Test I: 100\% correct). He then completed training to reorganize A-E relations and went on to show reorganized derived manding (Test II: 90\% correct). Finally, subsequent to retraining in the baseline A-E relations, John demonstrated the original derived mands (Test III: 90\% correct). 
Both Steven (diagnosed with autism) and Colm (diagnosed with autism) successfully completed Test I subsequent to experimental training procedures. Reversal procedures were not conducted with Steven, Colm, Gareth, or Paul due to time constraints.

Paul (diagnosed with autism) successfully completed training procedures but subsequently failed Test I (60\% correct). Paul was therefore exposed to exemplar training with the A-E stimuli (Set 2). This involved providing explicit reinforcement for the desired baseline derived relational mands (i.e., mand for $+2,+1,0,-1$, and -2 , with A, B, C, D, and E). Exemplar training trials were conducted in a manner similar to that for the boardgame practice trials described previously, with a mastery criterion of at least 26/30 correct trials across two successive 30-trial blocks. After Paul had completed exemplar training, he was exposed to training and testing with novel A-E stimuli (Set 3), and he then successfully completed Test I.

Gareth (attending ongoing ABA programs for a reported speech delay) was successful in completing training procedures but subsequently failed Test I (30\% correct). Gareth then underwent exemplar training with the A-E stimuli (Set 2). Subsequently, Gareth was exposed to training and test procedures with novel A-E stimuli (Set 3) and on this occasion successfully completed Test I.

\section{Discussion}

All seven participants ultimately demonstrated derived manding based on a derived transformation of function. Three of the participants also showed reorganized derived manding and a return to baseline derived manding.

Mary initially failed to show the reorganized derived relational manding, but succeeded subsequent to additional training in the reorganized A-E relations. This result is consistent with previous research that has documented difficulties with reversals of indirect relations. For example, normally developing adults and children have failed to adjust derived relational responding in accordance with changed contingencies when the change involved the indirect relations (i.e., in an A-B-C equivalence relation, reversal of A-B was shown but not of A-C) (Pilgrim, Chambers \& Galizio, 1995; Pilgrim \& Galizio, 1995). In addition, previous derived mand research has shown similar difficulties with reversing derived mands (Murphy \& Barnes-Holmes, 2009a, 2009b;). Participants in these studies failed to demonstrate reversed derived manding subsequent to training to reverse conditional discrimination. In the latter studies, extended training in reversed relations appeared to facilitate a reversal of derived manding when it failed to emerge, and the current findings concur insofar as extra training resulted in reorganized derived manding for Mary.

Paul and Gareth both initially failed to show derived manding and both, in turn, were exposed to an intervention involving exemplar training for the desired transformation of mand functions. Derived responding is thought to result from a history of multiple exemplars (see RFT; Hayes et al., 2001) and thus RFT predicts that exemplar training might facilitate the emergence of derived manding when it is found to be absent. The exemplar training procedure involved directly training the desired relational mands (mand for $+2,+1,0,-1$, and -2 , with A, B, C, D, and E, respectively), and both boys 
subsequently showed derived manding with a novel stimulus set. The facilitative effect of exemplar training for Paul and Gareth is consistent with our previous findings (Murphy \& Barnes-Homes, 2009a; Murphy et al., 2005) and with other studies that have used it to establish initially absent patterns of derived relational responding (Barnes-Holmes, Barnes-Holmes, Roche, \& Smeets, 2001a, 2001b; Luciano, Barnes-Holmes, \& Barnes-Holmes, 2001).

The current study has shown derived transformation of manding functions in accordance with a comparative relation, with both typically developing children and children with learning disorders. Although previously published studies have reported a transformation of functions with adults, the current study is the first to demonstrate the effect with children. The current results suggest, therefore, that the types of procedures, or at least the general approach, adopted here could be incorporated into language training programs for normally developing children and those with language deficits. Indeed, such language training could serve to establish relatively complex manding repertoires that extend beyond the transfer of mand function effects we reported in earlier articles

Earlier studies in the current program of research involved derived manding based on transfer through equivalence relations (e.g., a mand trained to A transfers to C via A-B-C). This earlier effect might be seen as a method for establishing synonymous mands for the same item, or for the same specific amount of items. The current study also involved derived manding for specific amounts of tokens, but the mand values were derived relative to each other (e.g., A is more than B, therefore, mand for +2 with $\mathrm{A}$, mand for +1 with $B$ ). It should be noted that although mands seemed to be evoked via a prior history of conditioned reinforcement (tokens and winning a game), it is possible that other factors exerted an influence, such as a history of compliance with rules.

Further research will be required to examine the role played by the participants' pre-experimentally established levels of verbal functioning. For example, all participants in the current study could (minimally) add and subtract single digits, and all except John had been involved in a previous study of derived manding (equivalence based) that could possibly have affected the current derived mand performances. Research into possible differences in derived manding in populations with and without ASD may also be informative.

Perhaps the current procedures could be adapted for classroom use in order to teach this complex type of relational manding. Imagine a teaching exercise similar to the current training procedure, in which a child is taught that -2 is less than -1 , which is less than 0 , which is less than +1 , which is less than +2 . This could involve a relational match-to-sample procedure using a set of printed numbers $(-2,-1,0,+1,+2)$ or textuals (two less, one less, zero, one more, two more) to train the comparative relations. This teaching could then be followed by a mand procedure during which preferred and nonpreferred reinforcers are presented. The child would be required to mand with one of the five printed numbers (or one of the five printed textuals) to obtain or remove vouchers for preferred or nonpreferred edibles. For example, a teacher could present a token-board and vouchers for preferred and nonpreferred items. If the teacher presented the board with one or two vouchers for preferred edibles "missing," the child must mand using the correct printed number (or printed text) for +2 or +1 , respectively. If the board is 
presented with vouchers for two preferred edibles and one or two vouchers for nonpreferred edibles, the child must mand for -1 or -2 , respectively. Providing this type of training and testing to establish derived transformations of mand functions may well serve to build relatively complex and flexible mand repertoires for children who might otherwise tend toward basic and rigid verbal behaviors.

\section{References}

AMERICAN PSYCHIATRIC ASSOCIATION. (2000). Diagnostic and statistical manual of mental disorders (4th ed.). Washington, DC: Author.

BARNES, D., BROWNE, M., SMEETS, P., \& ROCHE, B. (1995). A transfer of functions and a conditional transfer of functions through equivalence relations in three to six-year-old children. The Psychological Record, 45, 405-430.

BARNES-HOLMES, Y., BARNES-HOLMES, D., ROCHE, B., \& SMEETS, P. M. (2001a). Exemplar training and a derived transformation of functions in accordance with symmetry: I. The Psychological Record, 51, 287-308.

BARNES-HOLMES, Y., BARNES-HOLMES, D., ROCHE, B., \& SMEETS, P. M. (2001b). Exemplar training and a derived transformation of functions in accordance with symmetry: II. The Psychological Record, 51, 589-604.

DOUGHER, M. J., AUGUSTON, E., MARKHAM, M. R., GREENWAY, D. E., \& WULFERT, E. (1994). The transformation of eliciting functions through stimulus equivalence classes. Journal of the Experimental Analysis of Behavior, 62, 331-351.

DYMOND, S., \& BARNES, D. (1994). A transfer of self-discrimination response functions through equivalence relations. Journal of the Experimental Analysis of Behavior, 62, 251-267.

DYMOND, S., \& BARNES, D. (1995). A transformation of self-discrimination response functions in accordance with the arbitrarily applicable relations of sameness, more-than, and less-than. Journal of the Experimental Analysis of Behavior, 64, 163-184.

GREEN, G., STROMER, R., \& MACKAY, H. A. (1993). Relational learning in stimulus sequences. The Psychological Record, 43, 599-615.

HAYES, S. C., BARNES-HOLMES, D., \& ROCHE, B. (2001). Relational Frame Theory: A post-Skinnerian account of language and cognition. New York: Plenum.

LARAWAY, S., SNYCERSKI, S., MICHAEL, J., \& POLING, A. (2003). Motivating operations and terms to describe them: Some further refinements. Journal of Applied Behavior Analysis, 36, 407-414.

LUCIANO, C. M. S., BARNES-HOLMES, Y., \& BARNES-HOLMES, D. (2001). Early verbal developmental history and equivalence relations. International Journal of Psychology and Psychological Therapy, 1, 137-149.

MICHAEL, J. (1993). Establishing operations. Behavior Analyst, 16, 191-206. MURPHY, C., \& BARNES-HOLMES, D. (2009a). Establishing derived manding for specific amounts with three children: An attempt at synthesizing Skinner's Verbal Behavior with Relational Frame Theory. The Psychological Record, 59, 75-92.

MURPHY, C., \& BARNES-HOLMES, D. (2009b). Derived more/less relational mands with children diagnosed with autism. Journal of Applied Behavior Analysis, 42, 252-268. 
MURPHY, C., BARNES-HOLMES, D., \& BARNES-HOLMES, Y. (2005). Derived manding with seven children diagnosed with autism: Synthesizing Skinner's Verbal Behavior with Relational Frame Theory. Journal of Applied Behavior Analysis, 38, 445-462.

PILGRIM, C., CHAMBERS, L., \& GALIZIO, M. (1995). Reversal of baseline relations and stimulus equivalence: II. Children. Journal of the Experimental Analysis of Behavior, 63, 239-254.

PILGRIM, C., \& GALIZIO, M. (1995). Reversal of baseline relations and stimulus equivalence: I. Adults. Journal of the Experimental Analysis of Behavior, 63, 225-238.

REHFELDT, R. A. \& ROOT, S. L. (2005). Establishing derived requesting skills in adults with severe developmental disabilities. Journal of Applied Behavior Analysis, 38, 101-105.

ROCHE, B., \& BARNES, D. (1995). The establishment and electrodermal assessment of conditioned sexual responses. Experimental Analysis of Human Behavior Bulletin, 13, 26-29.

ROCHE, B., \& BARNES, D. (1996). Arbitrarily applicable relational responding and sexual categorization: A critical test of the derived difference relation. The Psychological Record, 46, 451-475.

ROSALES, R., \& REHFELDT, R. A. (2007). Contriving transitive conditioned establishing operations to establish derived manding skills in adults with severe developmental disabilities. Journal of Applied Behavior Analysis, 40, 105-121.

SIDMAN, M. (1971). Reading and auditory-visual equivalences. Journal of Speech and Hearing Research, 14, 5-13.

SKINNER, B. F. (1957). Verbal behavior. Englewood Cliffs, NJ: Prentice Hall.

STEELE, D., \& HAYES S. C. (1991). Stimulus equivalence and arbitrarily applicable relational responding. Journal of the Experimental Analysis of Behavior, 56, 519-555.

SUNDBERG, M. L., \& MICHAEL, J. (2001). The benefits of Skinner's analysis of verbal behavior for children with autism. Behavior Modification, 5, 698-724.

WHELAN, R., BARNES-HOLMES, D., \& DYMOND, S. (2006). The transformation of consequential functions in accordance with the relational frames of more-than and less-than. Journal of Experimental Analysis of Behavior, $86,317-335$. 


\section{The Analysis of}

\section{Subscribe Today!}

- The original publication of experimental or theoretical papers relevant to a behavioral analysis of verbal behavior.

- Keep up-to-date on key topics such as elementary verbal operants, multiple control, rule-governed behavior, epistemology, language acquisition, pedagogy, verbal behavior research methodology, and others.

- This annual publication is available for just $\$ 35.00$ to ABAI members!

Visit the ABAI website at www.abainternational.org and order your subscription from the on-line store today!

\section{Upcoming in the Next Issue:}

• Esch, J. W.; Esch, B. E.; McCart, J. D.; and Petursdottir,A. I. A Comparison of Echoic and Self-Echoic Repertoires in Young Children

- Sidener, T. M.; Carr, J. E.; Karsten,A. M.; Severtson, J. M.; Cornelius, C.E.; and Heinicke, M.R. Effects of Single and Multiple Verbal Operant Arrangements for Teaching Mands and Tacts

- Emmick, J. R.; Cihon, T. M.; and Eshleman, J. The Effects of Textual Prompting and Reading Fluency on the Acquisition of Intraverbals With Individuals With Developmental Disabilities

- Perez, W. F. and de Rose, J. C. Recombinative Generalization:An Exploratory Study in Musical Reading

- Stewart, K.; Hayashi, Y; and Saunders, K. Enhancing Vowel Discrimination Using Constructed Spelling

- Ribeiro, D.; Elias, C.; Goyos, C.; and Miguel, C. The Effects of Listener Training on the Emergence of Tact and Mand Signs by Individuals With Intellectual Disabilities

- Greer, R. D. and Longano, J. A Rose by Naming: How We May Learn How to Do It

- Schoneberg, T. Three Myths From the Language Acquisition Literature

- Bradley, K. P. and Poling, A. Defining Delayed Consequences as Reinforcers: Some Do, Some Don't, and Nothing Change

- Critchfield, T. S. Crucial Issues in the Applied Analysis of Verbal Behavior:A Review of Crucial Conversations: Tools for Talking When the Stakes are High 